\title{
Technological Transparency in the Age of Web 2.0: A Case Study of Interactions in Internet-Based Forums
}

\author{
Kamran Shaikh, Vivek Venkatesh, ${ }^{1}$ \\ Tieja Thomas, Kathryn Urbaniak, Timothy Gallant, ${ }^{2}$ \\ David I. Waddington and Amna Zuberi \\ Learning for Life Centre, Department of Education, Concordia University,
}

Canada

\section{Introduction}

Whether computers can be of benefit to the learning process has been a topic of discussion in the realm of educational technology research since the 1950s (Weigel, 2002). Computer technology has promised to revolutionize both teaching and learning in higher education (Slack \& Wise, 2005). With the popularization of the Internet in the early 1990s, programs dedicated to the democratization of information technology have assisted the general public to become members of electronic communities (Albernaz, 2002). Online communications were quickly adopted in education - course management systems have long been using bulletin boards and online forums to facilitate various types of interactions, including learner-learner, learner-teacher, teacher-teacher, teacher-content, and learner-content (Shaw \& Venkatesh, 2005).

However, in the first decade of the 21st century, with the advent of Web 2.0, the shape of online electronic communities began to change drastically. Online social interactions have seen an exponential growth since the increased adoption of technologies such as wikis and blogs. In this new age of the Web, users are given the power to control what content is displayed on their personal websites, and visitors to these websites are able to provide commentary using media as varied as text, audio and video.

Since 2004, commercial social networking applications such as Facebook, YouTube and Twitter have gained popularity across a variety of users, regardless of gender, culture, geographical regions and age. Facebook alone boasts more than 750 million active users worldwide (as of July 2011), and is ranked as the second most-visited site on the Internet after Google ${ }^{3}$. It is, therefore, rather disheartening to observe how theories of online learning have failed to take into account the paradigm shift we are seeing in the nature of social interactions through the Internet. Furthermore, existing theories have largely failed to account for the role online communities play in building and sustaining specialised forms of

\footnotetext{
${ }^{1}$ Joint first authors

${ }^{2}$ Joint second authors

${ }^{3}$ As ranked by Alexa - The Web Information Company (http://www.alexa.com)
} 
what Lave and Wenger (1991) have dubbed "communities of practice" - namely, a group of people who share an interest, a craft, or a profession.

Theoretical discussions of how the design of online interactions impact learning are scant, at best (McGee, Carmean \& Jafari, 2005; Venkatesh, Shaikh \& Zuberi, 2010). Part of the problem, we contend, lies in the fact that the pedagogical bases for orchestrating online interactions are based on learning theories and instructional design models derived from face-to-face instruction. This over-reliance on classic theories of learning has led directly to a paucity of research investigating how online learning actually happens "in the wild" (Lave \& Wenger, 1991). This holds true both within the educational realm and externally, in the wider Web 2.0 community.

In this chapter, we investigate learning in online forums which are focused on a particular interest, namely, heavy metal music. Even within this highly focused online community of metal fans, the data available for analysis is vast-individual forum members have often posted up to 20,000 times in as little as five years. We therefore decided to focus our analysis on a particular macro-level aspect of the forum: knowledge production processes. In order to understand these processes, we brought to bear a set of ideas about production that were originally espoused by John Dewey (1915). Dewey, in essence, thought that making production processes open and transparent was critical to helping citizens become more effective learners and agents. Applying these ideas to the forums, we theorized that relatively open knowledge production processes would help the heavy metal forum users become more savvy and engaged fans. As we will explain, this hypothesis held true to some extent. Yet our findings also indicated that the positive effects of open, transparent production processes can be mitigated by technocratic interactions between experts and novices.

\section{Theoretical framework}

\subsection{The genesis of technological transparency}

In School and Society, one of his first significant educational works, John Dewey (1915) emphasized the need for people to understand the basic mechanisms that underpin society. He argued that the rural dwellers of 19th century America, when compared to the inhabitants of Dewey's industrial Chicago, had possessed a better understanding of the technological processes that surrounded them. The inhabitants of rural America, Dewey claimed, understood how things were made, who in their communities was involved in the process, and the implications that this production process had for the lives of workers and consumers. This idea of developing an understanding of how things work is what is referred to as "technological transparency." Dewey thought that knowledge and in-depth understanding of the technologies that underpinned their society would afford citizens the opportunity to intervene in technological processes when necessary and would help them to be aware of how systems, structures or mechanisms around them function (Waddington, 2010). Dewey hoped that the industrial technologies of his day would become open to the understanding of citizens, rather than being closed off from their understanding. In this way, citizens would be able to make technologies work for them, rather than simply being shaped by prevailing technologies (Shaikh, Zuberi, Waddington, Thomas \& Venkatesh, 2011).

\subsection{Open and closed technologies}

\subsubsection{Defining open and closed technologies}

One interesting way, among others, to update Dewey's notion of technological transparency for the contemporary context is to ask about the degree to which today's technologies are 
transparent and open to our understanding. Thinking along these lines, one can classify technologies along a spectrum from "open" to "closed." Open technologies are technologies that allow the user (a) to understand how the technologies function on both a surface and a deeper level, and (b) to become involved in their overall construction, design, and management. It is this 'openness' that allows for the possibility of agency.

Wikis are one of the best examples of an open Web 2.0 technology - they allow for content to be completely user-generated and allow multiple users to collaborate to create artifacts. Although users do not have complete control of the overall design of the environment, they are the main force behind the development of the objects that populate the environment. If users disagree with specific content on a Wiki, they know that, given the control they may exert over the content in the environment, they have the agency to try to change it.

Closed technologies are those where the end-user is neither encouraged to understand how the technology works, nor participate in its design and evolution. This, from our perspective, results in an indifference towards making changes in the technology. The user accepts it as technology that "just works." The mechanisms necessary for change to occur, whether they are open channels of communication between users and designers or in-depth structural information about the technology, simply do not exist. Closed technologies are, in our current framework, entities where the construction and design choices open to users are limited to non-existent. Some knowingly accept that it cannot be changed and happily use the tool as it was designed, resulting in continued apathy towards promoting change in the technology itself. Facebook is an excellent example of a closed Web 2.0 technologyindividual owners can exert a certain amount of control over their profile or 'walls', but the overall design framework is rigid and the functioning of the system is not transparent to the user. This has the advantage of making the technology easy to use in that there are very few decisions for the user to make, but it is unlikely to stimulate interest in the way that the technology itself functions.

\subsubsection{The spectrum of openness and knowledge production processes}

While the notion of open and closed technologies was originally concerned with individuals understanding how technologies work, it can also be applied to the overall knowledge production process. We hypothesize that when individuals understand the processes at work behind knowledge production, it can have a profound effect in inspiring them to modify or create knowledge of their own. Both open and closed technologies are capable of facilitating the creation of new knowledge; however, they are different with regard to the processes through which new knowledge is produced. Knowledge production technologies like Wikipedia that are open have transformed people's conceptions of the knowledge production process-people have come to see themselves more as participants in the generation and construction of new knowledge. Furthermore, technologies like this have allowed for the valorization of new forms of knowledge (which traditionally may not have been considered worthwhile) and have contested the very nature of knowledge production. A notable example of technological transparency in the realm of knowledge production is in a class activity we recently designed at Concordia University. Learners enrolled in a graduate course on Online Communities in Concordia's Educational Technology program were required to modify a Wikipedia page detailing the topic of "Community of Practice" (http://en.wikipedia.org/wiki/Community_of_practice). They received minimal instruction regarding the process of knowledge production, were left to consult databases (both online 
and offline) and were encouraged to develop the artifact as a collective. The information the students posted on Wikipedia was not only vetted by the instructor and their in-class peers, but was also commented upon by reviewers of Wikipedia entries. As is to be expected in a classroom activity, the students were comfortable receiving feedback from their instructor and peers, but they were hesitant and surprised upon realizing that their work was stimulating much discussion by contributors to the Wikipedia page (see a summary of the discussions on http://en.wikipedia.org/wiki/Talk:Community_of_practice). Once the students began interacting with these reviewers-exchanging comments, debating the changes made to their work - they quickly began to realize that their work extended beyond a class assignment. They would often discuss in class what the online community had to say about their Wikipedia entries, and eventually developed a rich understanding of how Wikipedia entries were created and modified.

Through the use of an open technology, the students developed an understanding of the mechanisms involved in creating and modifying knowledge and information; they saw themselves as agents within the knowledge production process. Additionally, the external comments received altered the work significantly - the discussion on their Wikipedia entry led to the students generating content that would not have been created if they had been left to their own devices. Notably, even if a user's contribution is eventually rejected, the decision about the rationale for rejection will usually be relatively democratic and transparent. For example, each Wikipedia entry features a "Discussion" tab on which the edits are discussed, and there is also a "View History" option that allows the user to view how the article has evolved. These options allow both creators and consumers of the article to view which information is contested and to see how the knowledge has accreted (or has, in some cases, disappeared) and been validated over time. This allows the Wikipedia user to see inside knowledge production processes, thereby demystifying it, and this may, consequently, empower the user to become a contributor in his/her own right. In general, we contend that information that is produced through collective processes within open spaces can empower individuals to be both effective users and creators of the knowledge related to the technology in question.

The ability to create new knowledge has also meant a great shift from the traditional knowledge production process. It is no longer strictly hierarchical, where the expert is the sole arbiter of worth and is able to dictate to the novice. In forum technologies (as is the case with Wikipedia), any new information that is brought forward should usually be given some consideration for inclusion in the overall knowledge base. This very shift towards inclusion has changed the foundations of what has been traditionally perceived as knowledge production. Within successful open knowledge production frameworks, building new ideas becomes a participatory endeavor, thereby contributing to the democratization of digital spaces. The knowledge that is produced within open technological frameworks challenges the authority of expert knowledge. Individual expertise is validated and users gain a sense that they have an equal opportunity to be or become an expert and to disseminate their ideas worldwide. However, although open technologies offer learners the arguably beneficial opportunity to be both knowledge users and producers, their design does pose some challenges. For example, the lack of templates and specific guidelines supporting the development of some open designs may challenge their development and long-term survival. MySpace, for example, allowed creators to have complete control over the design of their personalized webspace. Though this may have provided a certain degree of creative license, MySpace decreased in popularity in part 
because of users' own muddled and complex designs which led to navigation and usability issues (Boyd, in press). In contrast, although it is a more closed technology, Facebook gained popularity through its cleaner, far more structured, less changeable environment.

The empirical research presented in this chapter draws upon data from online bulletin boards and forums, which we situate as being relatively open technologies. Web 2.0 forum technologies afford users an openness that is somewhat less than in the case of Wikis, but is still quite open - the underlying technology is fairly simple, user profiles are extensively customizable and key roles and responsibilities are allocated to users (e.g., moderation). In stark opposition to the Wikipedia example described above, which exemplified a democratic approach to knowledge production, our data and related analyses presented herein show that online forums typify technocratic approaches (Stabile, 1986) to the production and validation of new knowledge. In a technocratic approach, subject-matter expertise trumps other factors (e.g., socio-political) when it comes to decision-making. The research presented in this chapter suggests that online forums are more prone to technocratic styles of knowledge production because of participants' reliance on experts to make meaning from discussions.

\section{Methodology \& data sources}

To better comprehend the nature of online interactions in an era of social computing, we decided to observe thriving, self-selected online forum communities. We employed a qualitative case study of interactions and discussions amongst users of forums related to heavy metal music and culture. Heavy metal music and its fans have been the focus of largescale sociological research studies that describe the sub-culture from multiple perspectives, including those of music theory and lyrical content (Walser, 1993), as well as its history and tenuous relationship with popular media (Weinstein, 2000). There also exist case studies exploring the effect of heavy metal on the behaviours of adolescent fans (Arnett, 1991, 1993; Giles, 2003; Sibley, 1995), personality distinctions among followers of heavy metal (Hansen \& Hansen, 1991; King, 1985), and ethnographic research on face-to-face interactions between members of a community of heavy metal fans (Snell \& Hodgetts, 2007). The present research provides empirical analyses of online communities with the express objective of demystifying hierarchies of expertise and analysing how forum members interact to engage in knowledge production processes. We employed a selective sampling strategy of users based on their contributions to two online forums, namely Brave Boards:

http://www.bravewords.com/braveboards and Encyclopedia Metallum: http://www.metalarchives.com/, as well as one blog, Blabbermouth: http://www.roadrunnerrecords.com/ blabbermouth.net/. See figures 1, 2 and 3 for screen shots of these websites. Users were classified as super-users, i.e., individuals who have contributed in excess of 15,000 posts to either of these sites and exhibited high levels of content expertise, or browsers, i.e., individuals who primarily used the forums and blogs to seek information, and who typically refrain from posting.

We solicited participation via electronic mail and invited users to individual, hour-long video-recorded interview sessions. Videos contained screen captures of the users interacting within the online forums and blogs, as well as responses to interview questions posed by the research team. A semi-structured interview protocol was employed to elicit self-reflections and users' impressions of the forums. Users' and forum moderators' posts were used as a secondary data source. All data were collected in accordance with Canada's Tri-Council Policy on ethical conduct for research involving human participants. 
Register • FAQ • Login

It is currently 02 Aug 2011, 15:22

Board index Main Forums

All times are UTC $\cdot 5$ hours

Forum

Forum

The METAL Oracle

Metal Talk 24/7 No Rest For The Wicked!

Moderators: Metal_King, Nemesis, moshdrum69

The Tavern

Talk About Nothin' \& Everythin'!

Moderators: Metal_King, Nemesis, moshdrum69

Brave Feedback

Speak Your Mind!

Moderator: BravePilgrim

Announcements

Concert, \& 'Zine Promotion - Support The Scene \& Plug Your Stuff!

Moderators: Metal_King, Nemesis, moshdrum69

Musicians Forum

Information about Musicians, Gear, Promoters, Venues and More In Here

Moderators: Metal_King, Nemesis, moshdrum69

Hall of Fame

Archive Of Classic Threads From The Members of Our Community

\begin{tabular}{|c|c|c|}
\hline Topics & Posts & Last post \\
\hline 328 & 12167 & $\begin{array}{l}02 \text { Aug 2011, 15:19 } \\
\text { The Devil c }\end{array}$ \\
\hline 335 & 17649 & $\begin{array}{l}02 \text { Aug 2011, 15:21 } \\
\text { OldManAndChild }\end{array}$ \\
\hline 2 & 12 & $\begin{array}{l}02 \text { Aug 2011, 11:00 } \\
\text { Rook }\end{array}$ \\
\hline 163 & 1808 & $\begin{array}{l}02 \text { Aug } 2011,15: 00 \\
\text { Solarfall }\end{array}$ \\
\hline 40 & 414. & $\begin{array}{l}02 \text { Aug } 2011,14: 48 \\
\text { OldManAndChild } 0\end{array}$ \\
\hline 32 & 5864 & 09 Mar 2011, 12:57 \\
\hline
\end{tabular}

Carl

Fig. 1. Screen shot of Brave Boards forum home page (http://www.bravewords.com/braveboards).

\section{Encyclopaedia Metallum: The Metal Archives}

Message board

$\overline{\boldsymbol{T}}_{\text {FAQ }} \overline{\mathbf{a}}$ Search $\overline{\boldsymbol{\nabla}}_{\text {Register }} \overline{\mathbf{Q}}$ Login

It is currently Tue Aug 02, $20113: 28 \mathrm{pm}$

Music Talk

Metal discussion

Discussion about anything metal-related.

Recommendation Central

\#- Looking to take all of that pesky legwork out of your listening experlence? Click here.

For the musicians

FintI Forum for musicians - discuss songwriting, playing, tabs, instruments \& gear, techniques, etc. here.

Marketplace

Promotional forum

EIII Come spam your metal-related stuff here. METAL ONLY! DO NOT post advertisements anywhere else.

Trading board

21]E Set up music-related transactions with your fellow metalheads.

Off-Topic

The Tavern

For general discussions

Site Feedback
View unanswered posts | View active topic

$$
\begin{aligned}
& \text { Topics Posts } \\
& \text { Last post } \\
& 1025437987 \\
& \text { Tue Aug 02, } 20113: 27 \text { pm } \\
& \text { SatanicPotato } \rightarrow \square \\
& \text { Tue Aug 02, } 2011 \text { 3:25 pm } \\
& \text { Azathoth } 500 \rightarrow \square \\
& 294638675 \text { Tue Aug 02, } 20112: 43 \mathrm{pm} \\
& \text { Topics Posts Last post } \\
& 433819456 \text { Tue Aug 02, } 2011 \text { 11:25 am } \\
& \text { AAP }+\square \\
& \text { Tue Aug 02, 20113:16 pm } \\
& \text { BobM } \star \text { b } \\
& \text { Topics Posts } 2 \text { Last post } \\
& 2974259819 \text { Tue Aug 02, } 20113: 02 \text { pm } \\
& \text { Topics Posts Last post }
\end{aligned}
$$

Fig. 2. Screen shot of Encyclopedia Metallum forum home page (http:/ / www.metalarchives.com/board). 


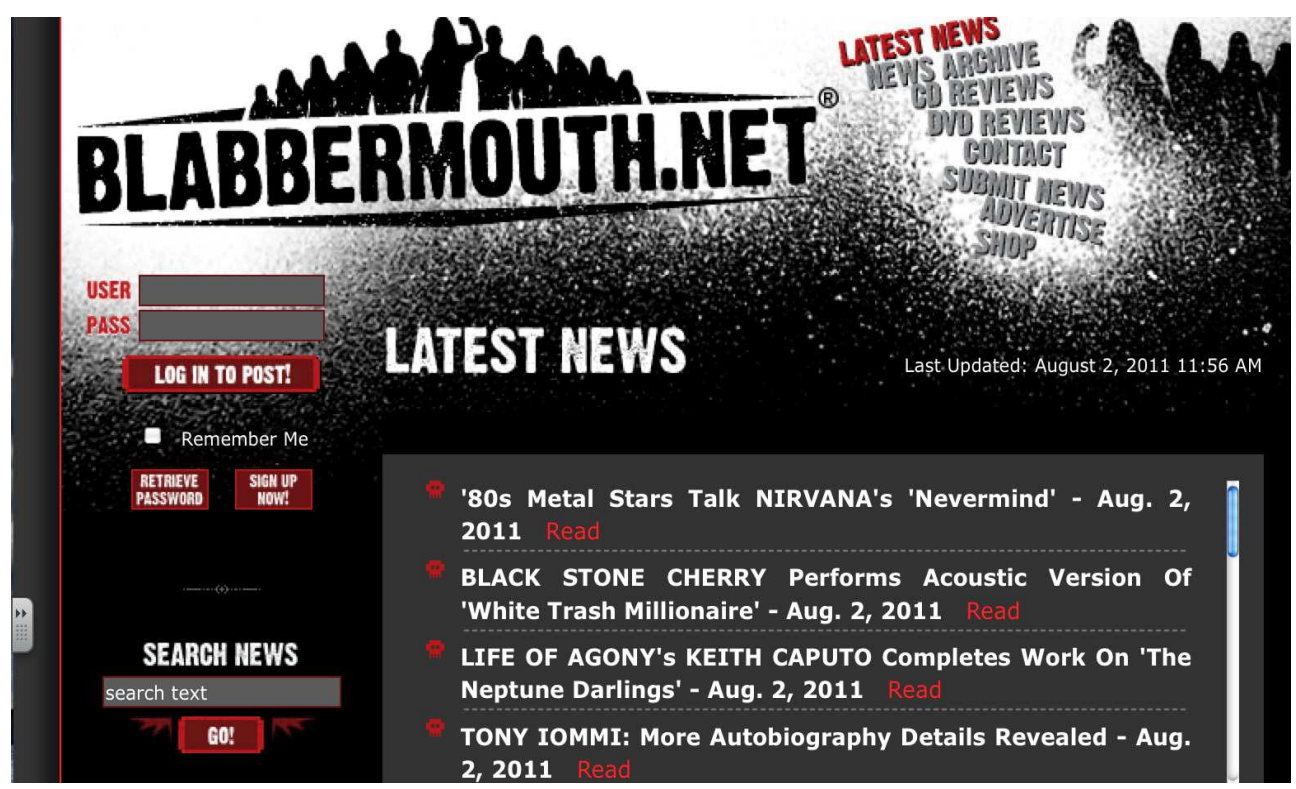

Fig. 3. Screen shot of Blabbermouth home page

(http://www.roadrunnerrecords.com/blabbermouth.net).

\section{Analysis \& discussion}

After exploring the postings on Brave Boards, Blabbermouth and Encyclopedia Metallum, we identified three super-users to help describe and validate open and closed knowledge production approaches within the online forums. We then developed predominant datadriven codes which encompassed themes from our theoretical framework of the spectrum of open and closed technologies. These codes, which are described below, include ownership and agency; transparency, democracy and technocracy; technocratic hierarchies of expertise; collaboration and validation; as well as accountability and citizenship.

\subsection{Super-user and browser profiles}

We explored narrative interview data from three super-users, all of whom agreed to divulge their real names. We also extracted these super-users' relevant posts from the forums to expand upon their interview responses. The prolonged amount of time that super-users have been members of forums, coupled with their extensive interactions within these forums, made their interviews and postings ideal units of analysis.

Our first super-user, Armen, goes by the screen name icedneonflames and has been a member of Brave Boards since 2001. Armen has earned Metal Guru status after having posted more than 10,000 times. A local musician, Armen originally joined the forum in search of other musicians with whom to have discussions. In the 10 years since Armen joined Brave Boards, he has posted 22,052 times (as of July 29, 2011) and logs in on a daily basis.

Jenny, another Metal Guru, and our second super-user goes by the screen name corvidae. She has been a member of Brave Boards for close to eight years and has 19,043 posts (as of July $29,2011)$. Although she does have a screen name, Jenny does not refrain from using her real 
name when online. Using the forum to help organize an annual "heavy-metal picnic" at Hyde Park in Toronto, Jenny demonstrates that there is considerable overlap between her online and offline lives.

Our third and final super-user, Ilya, originally joined Encyclopedia Metallum in order to broaden his musical tastes and learn more about heavy metal. Today, Ilya's wide knowledge base of heavy metal music, combined with his knowledge of forums and locating information on the Internet, make him a valuable expert in both the musical genre as well as forum and Internet usage. Ilya tends to log on daily to various forums to read what has been written and to make contributions.

In addition, we include analyses of interviews from two browsers, Derek and Mark (both pseudonyms, as they asked that their identities remain confidential), who typically visit Blabbermouth and Encyclopedia Metallum.

\subsection{Ownership and agency}

All three super-users highlighted the importance of holding themselves and others personally accountable within the forum. This accountability was sustained through self-policing measures such as addressing hostile (e.g., racist, homophobic) posts, reporting abusive behaviour to forum moderators, and signaling to other users if they post in the wrong section of the forum. During her interview, while browsing Brave Boards Jenny stopped to read a post and remarked, “... this doesn't belong here" and, after scrolling down the page noticed that another user had also pointed this out and indicated where the post should be placed on the forum. The ability to engage with and modify the contents of the forum was critical in developing users' sense of ownership and responsibility towards the forum.

Another device through which these super-users were able to gain a sense of ownership within the forum was through the use of different font colours and emoticons. Jenny stated that "Since I began using the forum I have always written in blue, it's my colour", and she went on to point out some users' unique signatures at the end of their respective posts.

Using various formatting options, Jenny personalised her presence within the forum. In addition, using pictorial representations such as emoticons, Jenny was better able to convey the intended tone of her posts. Additionally, she explained that the use of either full prose or 'text messaging' language influenced the ways in which posts are perceived within the forum:

"Some people use full sentences, some use text message language [...] it reflects their online personality. If someone uses [full prose], it might seem like too long a post and will be skipped over."

A factor contributing to the ways in which individuals use online forums is the amount of choice they have about how and when they choose to interact. For example, users of the Brave Boards site are free to set their status to either online (visible) or offline (invisible). Jenny argued that appearing 'visible' positively contributes to her forum identity:

“I'm an open person, I don't care if someone sees I'm online or not. I'm not trying to be anonymous. Others might want to be offline to avoid unwanted contact [and] retain their privacy."

While appearing 'visible' is arguably beneficial, one must consider how giving users a choice about whether or not to appear online affects their agency (Hodkinson, 2007). The option of remaining 'invisible' to Brave Boards participants can afford novice users the opportunity to become "legitimate peripheral participants" (Gannon-Leary \& Fontainha, 
2007; Lave \& Wenger, 1991). This enables users to observe their fellow heavy metal fans' interactions invisibly and derive personal edification from the discussions without the pressure of having to contribute.

Jenny explained that Brave Boards members can choose to sustain public interactions within the forum or they can choose to use the site as a meeting place that leads to more private interactions. Jenny also stated that she knows a lot of the users offline and that the forum is often used as a way of organizing offline activities like going to heavy metal shows. This suggests that providing users with a private email function may serve those who desire more anonymity with a suitable space. It remains important to consider, however, how the provision of a private email function would impact the openness of a given technology. It is conceivable that providing users with a concealed space in which to interact obstructs the transparency of knowledge production in the site.

\subsection{Transparency, democracy and technocracy}

One of the strengths of open technologies is the level of transparency in terms of communication, administration and functioning of the technology itself. Jenny stated, “... moderators are in another colour so you can easily identify them and can see when they're online so [...] you can go [read their posts] if you need to". Interestingly, while the moderators have ultimate control over the site content, thereby potentially hindering the openness of the knowledge production process, the fact that users could observe the process by which content was removed contributed positively to feelings of openness. This suggests that, similar to the case of Wikipedia, a clear process through which information is generated, contested, deleted, or accepted is crucial to fostering a transparent and democratic environment. It is perhaps this transparent process that encourages users to interact more frequently within structured forums such as Brave Boards. Further, it can be argued that the recognition gained from frequent interactions contributes to both the transparency and appeal of a forum. As Jenny points out,

"I'm a metal guru [...] it is an automated process that assigns status after a certain number of posts. [Some users] might have been on longer than me, but have posted less and are still at a lower rank."

We observed elements of technocracy when analyzing super-users' interactions with other members. Jenny is active in two of the five Brave Boards feedback threads. These threads exist to enable users to give feedback and provide critiques to the administrators of the forum beyond the simple 'reporting' feature used to flag trolling behaviours and spam. Jenny contributed to a feedback thread on new vertical advertisements on the site. Brave Boards users disliked this format of advertising and although they realized the site does need to make revenue, there was also a sense of futility in resisting the advertisements. Jenny vented:

"I think it's more the staff not being paid by selling the magazine anymore? Not sure, just speculating ... even if the ads need to be there, why the same ad on both sides? ... And the overlapping is stupid. Sizing needs to be fixed."

Ultimately, the advertisements did remain on the forum but have been configured so they interfere less with the users' experiences. This is an example of "closedness" on the Brave Boards which does not benefit the users or their heavy metal learning experience. The users dislike the ads and find them distracting, but can only avoid them if they use software such as AdBlock or specific browsers which duplicate this functionality. 
The other feedback thread Jenny participated in centers around users exerting control over the content posted in a thread. For example, Jenny contributed to a discussion about a user who disliked photo quotes, and who also complained of being unable to delete past posts. In her response to this user, Jenny was critical of his attitude and motive:

"Why [must you be so] antagonistic? We're a bunch of cool people with a few idiots and trolls. Do you want to be a troll or be a cool guy? It's feedback man, no need to be a douche."

Afterwards, the original poster is told by a couple of moderators that it is possible to delete past posts, and is asked to be more thoughtful about the content of the thread. It is also made clear to the original poster by these moderators that the site is fine as it is:

“... you have been here 29 days, this version of the board has been active 9 years. If it's not broken, there is no need to fix it. If you really dont like it here, find a new forum."

"Hey n00b, you dont think in the +9 years this version of the board has been around (or the +12 years that Bravewords has had a forum) that there has never been a Jake E Lee Thread? Well excuse us veterans who may not care to add our two cents again to a post like that unless we are bored or choose not to respond to which Iron Maiden record is the best. We have done it before."

These examples underline the fact that users' contributions are not viewed equally; we explore this inequality in a subsequent section on hierarchies of expertise. Consider also the following example from a thread in the feedback section, by a moderator of Brave Boards called +inertia+, who responds to complaints about the power being exerted by moderators. Below is +inertia+'s response to this criticism:

“... if you feel strongly enough that I don't deserve to run this place, find me a minimum of 60 users with a post count of 2500 or more that think I'm impartial and "WELL ABOVE (morally speaking) every other poster" and I will gladly step aside. With $3000+$ members that's less than $2 \%$ of the users."

In his interview, when viewing a forum topic comparing classic heavy metal albums, Armen reinforces the technocracy exerted by super-users regarding the types of knowledge that can be discussed on the forum:

“... Not this shit again; opinions are not going to change when comparing Iron Maiden to Judas Priest, or [comparing] Megadeth to Metallica ... everyone has seen the classic question posts, so there is nothing new to add."

This can be interpreted as exclusionary since newer members have not been on the site for seven or ten years and do not know that questions about comparisons between genres of metal as propagated by mainstream bands have been addressed extensively on the forum. Other examples that support technocratic distinctions include a quote from Derek, one of the participants classified as a browser, and a veteran of the metal sub-culture, who stated:

"People get bothered by the post counts. It creates hierarchies. If [one] guy has 200 posts and [another] guy literally has 35,000 posts it is like 'you newbie, why are you saying this, you have no role here."

Derek continues to say that he himself would not give a user with a high post count more credibility, but recognizes that other users might. Jenny confirms Derek's sentiments: "I don't 
get picked on that much either because of seniority". Armen also spoke of the value placed on users with an elevated status, like Neil Kernon, an award-winning music producer:

“... [Neil's comments] will be held in more importance...I can't disagree with him... he has a Grammy... people agree with him because he is Neil Kernon."

\subsection{Technocratic hierarchies of expertise}

The analysis of the interview data with the super-users and their postings within Brave Boards led to the identification of three types of forum users with respect to expertise: the novice user (with little to no expertise), the self-proclaimed expert (a person new to the forum who claims to have extensive knowledge in the subject) and the user-accepted expert (a person who has invested substantial time in contributing to the forum and has demonstrated their knowledge to other users).

Three types of interactions with technocratic dimensions were derived from the varying types of expertise: novice with self-proclaimed expert, novice with user-accepted expert and self-proclaimed expert with user-accepted expert. These three novice-expert interactions are manifested through questions posted on the forum by the novices, which are in turn answered by the experts. In such situations, we remarked that novices do not distinguish between the self-proclaimed experts' and the user-accepted experts' responses, leading to a somewhat blind acceptance of the answer to a query, regardless of its source or validity. The main distinguishing factor is the time invested in the forum, with the user-accepted experts contributing more to discussions within the forum. As a result of prolonged interactions with each other, the user-accepted experts tend to form a smaller clique and act as the forum's experts. When discussing various topics on one forum with another long-time user, super-user Armen simply stated, "[w]e are the experts". This clique of user-accepted experts governs itself and its members interact with each other using language which would otherwise be considered unbecoming. Jenny outlined this attitude of homophily (McPherson, Smith-Lovin \& Cook, 2001) while discussing novices and self-proclaimed experts making derogatory remarks to user-accepted experts:

"It's ok to talk shit and make unacceptable remarks with each other because we know each other [...] but if it's someone who hasn't been around for a while, we won't accept that."

\subsection{Collaboration and validation}

The transparency of knowledge production processes in online environments has instigated a shift in the traditional knowledge production and dissemination process. One substantial change is that sources can be referenced directly and checked instantaneously. Not surprisingly, all three super-users of the Brave Boards forum cited placing links to other websites on the forum as a common practice. Ilya stated that:

"Links to YouTube videos of the band will be posted so that you can [check them out]

when discussing threads where people are seeking new music to listen to."

By branching off of the site and making links to outside information, users are able to add to, as well as validate, existing information. Armen and Jenny both pointed out that, when presented with questionable information on Brave Boards, they would check another source, like Encyclopedia Metallum. Armen continued, "the post points to information to be checked and [outside sources] can either confirm the information or disprove it". 
A number of metal fans use blogs to keep in touch with the happenings and latest developments in the world of heavy metal. Participants such as Derek and Mark contribute to the 'news-worthiness' of blog entries, by rating them on sites like Blabbermouth. Mark talked in depth about Blabbermouth being one of the three sites he checks daily to keep abreast of heavy metal news. Mark noted that Blabbermouth added a way to rate news items and other users' comments by clicking on either an icon of devil horns (like) or a thumbs-down (dislike):

"What I think is really neat, what they did recently, because I tend to get lazy sometimes, when I want to put a comment down if it is any hassle, like if I try to put it down and it is not going in I won't bother ... but I am always logged in anyway ... but most of the time it works. But they did just start [...] doing for each comment ... they have two signs, a devil's sign and a thumbs-down."

\subsection{Accountability and citizenship}

As discussed, users of Brave Boards highlighted the importance of holding themselves and others personally accountable for their actions within the forum. Implicit in this forum is a culture of practices and ideals, grounded in a technocratic approach that, despite its drawbacks, supports the effective functioning of this collaborative online environment. By adhering to such norms, users share the responsibility for the future of the common space. Moreover, as Armen explained, users work together in order to cultivate a safe and welcoming environment for all members of the community. Armen noted that, when confronted by someone outside of the community, or outside of the clique, the other members will "protect their own". Jenny also stated that, having been a member for such a long time and attaining Metal Guru status, she feels responsible for upholding the norms of the forum like calling out trolls, identifying spam bots, and respecting what she termed the "ebb and flow" of the forum. In the case of individuals who are typically isolated from mainstream society, as heavy metal fans arguably are, the creation and availability of online environments can be particularly beneficial with regards to identity, citizenship, and feelings of belonging (McPherson et al., 2001). The trust that is garnered through positive interactions between users of Brave Boards helps support the creation of a space in which users can build relationships, feel both accepted and respected, as well as find and foster communities in which they belong. An excellent example of the ways in which online forums bolster community cohesion can be found in Jenny's interview. She explained that many relationships cultivated through online forums transfer to offline environments. One example involved her finding a place to stay while abroad at a heavy metal show. When asked if she knew the person Jenny stated that "yes I knew him, online [...] but it was the first time we met [offline]." Further, she recounted the fact that her involvement in the Brave Boards forum has enabled her to spearhead an increasingly popular annual heavy metal picnic, "I host a yearly heavy metal picnic at Hyde Park [...]; lots of people come out [...]; some from the forum."

\section{Conclusions}

More than 100 years ago, Dewey noted that, in order for students to become critical consumers and producers of knowledge and effective actors in social contexts, they needed to understand how technological processes function. In online forums, we believe that we see an example of a relatively open technological process - a process which, despite technocratic elements, allows knowledge to be created in a reasonably transparent fashion. 
Given our analysis of interactions, we believe forums can empower users to think critically and act as agents of knowledge production. It is also possible that this sense of agency will transfer to the overall social context. Though the forums we highlight are not completely open or transparent technologies, we do not foresee this as limiting the production of new knowledge or the interactions between users. Within these online communities, there do exist rules and hierarchies which govern the validation of such knowledge. As seen in our analysis, these rules, which are enforced through an inter-connected and complex network of expert and novice users, are dynamic in nature and constantly evolve with the needs and individual preferences of users.

Our analysis points out that users and creators who are aware of how open knowledge production technologies function can develop substantial new possibilities for agency. They can choose to use the tools to create new knowledge, intervene in existing knowledge production processes, and criticize the means of knowledge production. However, from our analysis, it is clear that even a relatively open system can result in the propagation of technocratic structures. These structures add richness and authority to the discussions and facilitate some types of interaction between experienced users, but they also hinder new users in certain ways. Given the limited scope of our analysis, it is important that further research be conducted into the potential of Internet-based forums to create democratic spaces that promote knowledge production processes. Despite these technocratic structures, the opportunity for new users to enact change and to become prominent members of the community does existthe very openness and transparency of the community allows them to see a clear path to increased participation and respect within the community.

\section{Acknowledgements}

This project was made possible through research monies obtained by authors Venkatesh, Waddington and Shaikh from Concordia University's Office of the Vice-President Research and Graduate Studies' Seed Funding program and doctoral bursaries obtained by authors Shaikh and Zuberi from le fonds québecois de recherche sur la société et la culture. Portions of the theoretical framework presented in this chapter appear in an article prepared by the authors for the Spring 2011 edition of Canadian Issues, published by the Association for Canadian Studies. Special thanks to Blake Judd from Chicago-based extreme metal band Nachtmystium for providing personal insight into how he used MySpace to communicate with fans. We also thank David Perri from Brave Words and Bloody Knuckles, and Rashi Khilnani from Radio Canada International for publicizing our research in popular media outlets, and in the process, helping us recruit participants from the heavy metal community.

\section{References}

Albernaz, A. (2002). The Internet in Brazil: From digital divide to democracy. Proceedings of the 14th Annual Conference of the Association of Academic Programs in Latin America and the Caribbean. Available at: http:/ / www.aaplac.org/library/AlbernazAmi03.pdf

Arnett, J. (1991). Heavy metal music and reckless behavior among adolescents. Journal of Youth and Adolescence, 20(6), 573-592.

Arnett, J. (1993). Three profiles of heavy metal fans: A taste for sensation and a subculture of alienation. Qualitative Sociology, 16, 423-443.

Boyd, D. (in press). "White Flight in Networked Publics? How Race and Class Shaped American Teen Engagement with MySpace and Facebook." In Digital Race 
Anthology (L. Nakamura \& P. Chow-White, eds.). New York, NY: Routledge. Available at: http://www.danah.org/papers/2009/WhiteFlightDraft3.pdf

Dewey, J. (1915). The School and Society (2nd edtion). Chicago,IL: University of Chicago Press.

Gannon-Leary, P.M. \& Fontainha, E. (2007). Communities of practice and virtual learning communities: Benefits, barriers and success factors. eLearning Papers, 5. Barcelona, Spain: P.A.U. Education

Giles, D. (2003). Media psychology. London, UK: Lawrence Erlbaum Associates.

Hansen, C.H. \& Hansen, R.D. (1991). Constructing personality and social reality through music: Individual differences among fans. Journal of Broadcasting and Electronic Media, 35(3), 335-351.

Hodkinson, P. (2007), Interactive online journals and individualisation. New Media and Society, 9 (4), 625-650.

King, P. (1985). Heavy Metal: A new religion. Journal of the Tennessee Medical Association, 78, 754-755.

Lave, J. \& Wenger, E. (1991). Situated learning: Legitimate peripheral participation. Cambridge, UK: Cambridge University Press.

McGee, P. Carmean, C. \& Jafari, A. (2005). Course Management Systems for Learning: Beyond Accidental Pedagogy. Hershey, PA: Idea Group, Inc.

McPherson, M., Smith-Lovin, L. \& Cook, J. M. (2001). Birds of a feather: Homophily in social networks. Annual Review of Sociology, 27, 415-444.

Shaikh, K., Zuberi, A., Waddington, D., Thomas, T., \& Venkatesh, V. (2011). A manifesto for technological transparency in the age of Web 2.0. Canadian Issues, Spring 2011, 8790.

Shaw S., \& Venkatesh, V. (2005). The missing link to enhanced course management systems: Adopting learning content management systems in the educational sphere. In P. McGee, C. Carmean \& A. Jafari (Eds.), Course Management Systems for Learning: Beyond Accidental Pedagogy (pp. 206 - 231). Hershey, PA: Idea Group, Inc.

Sibley, D. (1995). Geographies of exclusion: Society and difference in the West. New York: Routledge.

Slack, J. D., \& Wise, J. M. (2005). Culture and technology: A primer. New York, NY: Peter Lang Publishing

Stabile, D. R. (1986). Veblen and the political economy of the engineer: The radical thinker and engineering leaders came to technocratic ideas at the same time. The American Journal of Economics and Sociology, 45 (1), 43-44.

Snell, D. \& Hodgetts, D. (2007). Heavy metal, identity and the social negotiation of a community of practice. Journal of Community and Applied Social Psychology, 17 (6), 430-445

Venkatesh, V., Shaikh, K. \& Zuberi, A. (2010). Topic Maps as Indexing Tools in the Educational Sphere: Theoretical Foundations, Review of Empirical Research and Future Challenges. In Perusich, K. (Ed.). Cognitive Maps (pp. 1-12). Vienna, Austria: In-Tech.

Waddington, D. I. (2010). Scientific self-defense: Transforming Dewey's idea of technological transparency. Educational Theory, 60 (5), 621-638.

Walser, R. (1993). Running with the devil: Power, gender and madness in Heavy Metal music. Hanover, NH: University Press of New England.

Weigel, V. (2002). Deep learning for a digital age: Technology's untapped potential to enrich higher education. San Francisco, CA: Jossey-Bass Publishing.

Weinstein, D. (2000). Heavy Metal: The Music and its Culture. Cambridge, MA: DaCapo Press 


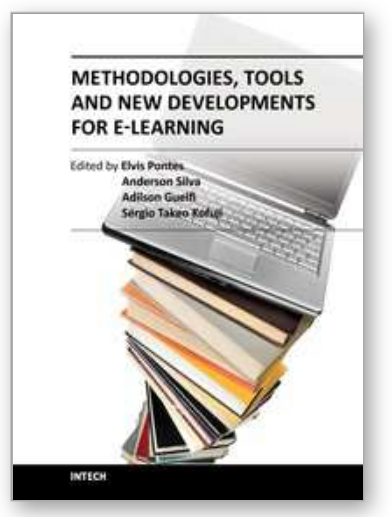

\author{
Methodologies, Tools and New Developments for E-Learning \\ Edited by Dr. Elvis Pontes
}

ISBN 978-953-51-0029-4

Hard cover, 332 pages

Publisher InTech

Published online 03, February, 2012

Published in print edition February, 2012

With the resources provided by communication technologies, E-learning has been employed in multiple universities, as well as in wide range of training centers and schools. This book presents a structured collection of chapters, dealing with the subject and stressing the importance of E-learning. It shows the evolution of Elearning, with discussion about tools, methodologies, improvements and new possibilities for long-distance learning. The book is divided into three sections and their respective chapters refer to three macro areas. The first section of the book covers methodologies and tools applied for E-learning, considering collaborative methodologies and specific environments. The second section is about E-learning assessment, highlighting studies about E-learning features and evaluations for different methodologies. The last section deals with the new developments in E-learning, emphasizing subjects like knowledge building in virtual environments, new proposals for architectures in tutoring systems, and case studies.

\title{
How to reference
}

In order to correctly reference this scholarly work, feel free to copy and paste the following:

Kamran Shaikh, Vivek Venkatesh, Tieja Thomas, Kathryn Urbaniak, Timothy Gallant, David I. Waddington and Amna Zuberi (2012). Technological Transparency in the Age of Web 2.0: A Case Study of Interactions in Internet-Based Forums, Methodologies, Tools and New Developments for E-Learning, Dr. Elvis Pontes (Ed.), ISBN: 978-953-51-0029-4, InTech, Available from: http://www.intechopen.com/books/methodologies-toolsand-new-developments-for-e-learning/technological-transparency-in-the-age-of-web-2-0-a-case-study-ofinteractions-in-internet-based-foru

\section{INTECH}

open science | open minds

\section{InTech Europe}

University Campus STeP Ri

Slavka Krautzeka 83/A

51000 Rijeka, Croatia

Phone: +385 (51) 770447

Fax: +385 (51) 686166

www.intechopen.com

\section{InTech China}

Unit 405, Office Block, Hotel Equatorial Shanghai

No.65, Yan An Road (West), Shanghai, 200040, China 中国上海市延安西路65号上海国际贵都大饭店办公楼 405 单元

Phone: +86-21-62489820

Fax: +86-21-62489821 
(C) 2012 The Author(s). Licensee IntechOpen. This is an open access article distributed under the terms of the Creative Commons Attribution 3.0 License, which permits unrestricted use, distribution, and reproduction in any medium, provided the original work is properly cited. 